\title{
Mechanisms of chloramphenicol resistance in Haemophilus influenzae in the United Kingdom
}

\author{
MAIR POWELL and D. M. LIVERMORE
}

Department of Medical Microbiology, The London Hospital Medical College, Turner Street, London E1 2AD

\begin{abstract}
Summary. Of 2458 isolates of Haemophilus influenzae examined in a recent British survey, 42 were resistant to chloramphenicol. Two resistant isolates were of type b and 40 were non-capsulate. Spectrophotometric assay showed that all the resistant isolates produced chloramphenicol acetyltransferase (CAT). CAT activity did not increase following growth on heated blood agar containing chloramphenicol $2 \mathrm{mg} / \mathrm{L}$ but was reduced by $84-98 \%$ when extracts were treated for $30 \mathrm{~min}$ with $5^{\prime}, 5^{\prime}$ dithiobis-2-nitrobenzoate. These data suggest that $H$. influenzae CATs resemble the Type-II CATs produced by enterobacteria. Extrachromosomal DNA was detected in five only of the 42 resistant isolates and cured derivatives of two plasmid-containing strains retained their chloramphenicol resistance. These results suggest that the CAT gene is located on the chromosome.
\end{abstract}

\section{Introduction}

Chloramphenicol-resistant strains of Haemophilus influenzae are uncommon in the United Kingdom and accounted for $19(1.0 \%)$ only of 1841 isolates examined during a multi-centre British survey in 1981 (Philpott-Howard and Williams, $1982)$ and for $42(1.7 \%)$ of 2458 isolates examined during a similar survey in 1986 (Powell et al., 1987). All the resistant isolates from the earlier survey were shown by bioassay (Manten et al., 1976) to inactivate chloramphenicol and it was inferred that they produced chloramphenicol acetyltransferase (CAT; E.C. 2.3.1.28). Production of CAT by chloramphenicol-resistant $H$. influenzae has been observed by several other workers (Roberts et al., 1980; Azemun et al., 1981). In some cases, the genes coding for the enzyme were plasmid-borne (Roberts and Smith, 1980) but in others the genes had been integrated into the chromosome (Mendelman et al., 1984).

Roberts et al. (1982) examined CAT-producing isolates of $\boldsymbol{H}$. influenzae from Canada, France, The Netherlands, Thailand and the USA and detected enzymes that were biochemically similar to the Type-II CATs of enterobacteria, i.e., they were inhibited by $5^{\prime}, 5^{\prime}$-dithiobis-2-nitrobenzoate (DTNB). Strains of $H$. influenzae producing CAT similar to the DTNB-resistant Type-I and -III CATs of enterobacteria have not been reported. Recently, however, non-enzymatic chlorampheni-

Received 26 Nov. 1987; accepted 18 Feb. 1988. col resistance has been observed in $H$. influenzae isolates from the USA, apparently associated with the loss of an outer-membrane protein of mol. wt 40000 (Burns et al., 1985).

In the present study the biochemical mechanism and genetic basis of chloramphenicol resistance of $H$. influenzae isolates collected during the 1986 antibiotic resistance survey in the UK (Powell et al., 1987) have been examined.

\section{Materials and methods}

\section{Strains}

Identification of species, antibiotic sensitivity testing and serotyping were done as described by Powell et al. (1987). Forty-two isolates of $H$. influenzae from the survey, including two of type $b$, were classified as chloramphenicol-resistant, i.e., the MIC for these strains was $\geqslant 4 \mathrm{mg} / \mathrm{L}$ or the zone of inhibition produced by a $10-\mu \mathrm{g}$ chloramphenicol disk (Oxoid) was $<20 \mathrm{~mm}$ diameter in tests on DST Agar (Oxoid) supplemented with lysed blood $0.25 \% \mathrm{v} / \mathrm{v}$ and nicotinamide adenine dinucleotide (NAD) $(10 \mathrm{mg} / \mathrm{L})(\mathrm{BDH}$, Poole, Dorset). The results with 30 isolates fulfilled both criteria; ten were considered to be resistant on the basis of MIC values alone and two from the results of disk tests alone. Three chloramphenicol-sensitive isolates for which the inhibition zone diameter was $\geqslant 30 \mathrm{~mm}$ and MIC of chloramphenicol was $\leqslant 0 \cdot 25 \mathrm{mg} / \mathrm{L}$ were included as controls.

The 42 resistant isolates were obtained from laboratories in Aberdeen (1), Birmingham (2), Bristol (5), Inverness (1), Liverpool (8), London (8), Manchester (1), Newcastle-upon-Tyne (4), Nottingham (7), Plymouth (3) and Portsmouth (2). 
All the chloramphenicol-resistant isolates were resistant also to tetracycline (zone $<20 \mathrm{~mm}$ with a $10-\mu \mathrm{g}$ disk and MIC $\geqslant 4 \mathrm{mg} / \mathrm{L}$ ). Thirteen isolates, including one of the type-b strains, produced $\beta$-lactamase. Two chloramphenicol-resistant $\beta$-lactamase-producing strains were also resistant to trimethoprim (zone $<20 \mathrm{~mm}$ with a $1 \cdot 25$ $\mu \mathrm{g}$ disk and $\mathrm{MIC} \geqslant 2 \mathrm{mg} / \mathrm{L}$ ) and sulphamethoxazole (zone $<20 \mathrm{~mm}$ with a $100-\mu \mathrm{g}$ disk and $\mathrm{MIC} \geqslant 32 \mathrm{mg} / \mathrm{L}$ ).

Escherichia coli strain 116, obtained from $\mathrm{Dr}$ A. A. Said (PhD Thesis, University of London, 1988), containing plasmids of mol. wts $70,40,28,10$ and $6\left(10^{6}\right)$, was used as a control during determinations of plasmid mol. wts. Reference $E$. coli strains producing CAT of types I, II and III were obtained from the National Collection of Type Cultures, Colindale, London, (NCTC nos. 50055, 50128 and 50022 respectively).

\section{Preparation of extracts containing $C A T$}

Organisms grown overnight at $37^{\circ} \mathrm{C}$ on fresh heated blood agar plates with or without chloramphenicol $2 \mathrm{mg} / \mathrm{L}$ in an atmosphere of $\mathrm{CO}_{2} 5 \%$ and air $95 \%$ were suspended in $0.2 \mathrm{M}$ Tris- $\mathrm{HCl}$ buffer, $\mathrm{pH} 8.0$, to an optical density at $450 \mathrm{~nm}\left(\mathrm{OD}_{450}\right)$ of 0.800 (SP 1700 Spectrophotometer, Pye Unicam Ltd, Cambridge). Each suspension was mixed with an equal volume of an alkaline solution ( $\mathrm{pH} 8.0$ ) containing $2 \mathrm{M} \mathrm{NaCl}, 0.02 \mathrm{M}$ EDTA and sodium dodecyl sulphate (SDS) $0.1 \% \mathrm{w} / \mathrm{v}$, and incubated for $1 \mathrm{~h}$ at $37^{\circ} \mathrm{C}$ to lyse the cells and release CAT.

\section{Assays of CAT activity}

The spectrophotometric method of Shaw and Brodsky (1968) was used. The reaction mixture, $1 \mathrm{ml}$ in volume, contained $0.1 \mathrm{~mm}$ acetylcoenzyme A (sodium salt) (Sigma), 0.5 mM DTNB (Sigma) and 0.1 mM chloramphenicol (Parke-Davis and Co., Pontypool, Gwent) in $0.12 \mathrm{M}$ Tris- $\mathrm{HCl}$ buffer, $\mathrm{pH} \mathrm{8.0.} \mathrm{The} \mathrm{reaction} \mathrm{was} \mathrm{begun}$ by adding $100 \mu \mathrm{l}$ of cell extract, and the absorbance at $412 \mathrm{~nm}$ was monitored continuously at $37^{\circ} \mathrm{C}$ in a Pye Unicam SP1700 dual beam spectrophotometer linked to a chart recorder. The reference cuvette contained the same mixture without chloramphenicol.

Enzyme activity was calculated by the method of Shaw (1975). One unit was defined as the amount of enzyme which acetylated $1 \mu \mathrm{mol}$ of chloramphenicol $/ \mathrm{min}$ at $37^{\circ} \mathrm{C}$. To relate OD to mass, a $10-\mathrm{ml}$ suspension of cells in water was adjusted to an $\mathrm{OD}_{450}$ of 0.8 , then dried to constant weight in a dessicator. An average was taken of three dry-weight estimations with each of three strains of $H$. influenzae and used to express CAT activity in units/mg dry weight.

To investigate inhibition of CAT by DTNB, $100 \mu \mathrm{l}$ of cell extract was added to each of two cuvettes containing $0.1 \mathrm{~mm}$ acetylcoenzyme A and $0.5 \mathrm{~mm}$ DTNB in $1 \mathrm{ml}$ of $0.12 \mathrm{M}$ Tris- $\mathrm{HCl}$ buffer, $\mathrm{pH} \mathrm{8.0.} \mathrm{After} \mathrm{incubation} \mathrm{for}$ $30 \mathrm{~min}$ at $37^{\circ} \mathrm{C}, 100 \mu \mathrm{l}$ of distilled water was added to the reference cuvette and $100 \mu \mathrm{l}$ of $1 \mathrm{mM}$ chloramphenicol solution in distilled water was added to the test cuvette. The $\mathrm{OD}_{412}$ was then recorded as described above.

\section{Plasmid extraction and electrophoresis}

All the resistant isolates were examined for extrachromosomal DNA by the method of Kado and Liu (1981). Cells were lysed by incubation for $1 \mathrm{~h}$ at $56^{\circ} \mathrm{C}$ in $250 \mu \mathrm{l}$ of a solution containing SDS $3 \% \mathrm{w} / \mathrm{v}$ in $50 \mathrm{~mm}$ Tris adjusted to $\mathrm{pH} 12.6$ by addition of $2 \mathrm{M} \mathrm{NaOH}$. After addition of an equal volume of phenol:chloroform $(1: 1 \mathrm{v}: \mathrm{v})$ the solution was emulsified by shaking gently and then centrifuged for $10 \mathrm{~min}$ at $12000 \mathrm{~g}$. The upper, aqueous, phase was removed and $20 \mu \mathrm{l}$ was mixed with $5 \mu \mathrm{l}$ of bromocresol purple $0.25 \%$ in glycerol $50 \%-0.05 \mathrm{M}$ Tris. Samples $(12 \mu \mathrm{l})$ were then loaded on agarose gels $0.8 \% \mathrm{w} / \mathrm{v}$ and separated by electrophoresis at $100 \mathrm{~V}$. After electrophoresis, the plasmids were stained with ethidium bromide and visualised by UV transillumination.

Eight of the strains in which plasmids were not detected by this method were further examined by the procedures of Meyers et al. (1976) and Bennett et al. (1986). In the former, cells were lysed by suspending them in a solution of $1 \mathrm{~mm}$ EDTA and sucrose $25 \% \mathrm{w} / \mathrm{v}$ in $10 \mathrm{~mm}$ Tris-acetate, $\mathrm{pH} 8$, for $1 \mathrm{~h}$ at $37^{\circ} \mathrm{C}$. In the latter, a solution of lysozyme $1 \mathrm{mg} / \mathrm{ml}$ in $50 \mathrm{~mm}$ glucose, $10 \mathrm{mM}$ EDTA and $25 \mathrm{mM}$ Tris- $\mathrm{HCl}, \mathrm{pH} 8$, was used to lyse the cells by exposing them to this mixture for $15 \mathrm{~min}$ at room temperature. Plasmids extracted by these procedures were separated by electrophoresis as described above.

\section{Plasmid curing}

Three strains containing single plasmids were grown overnight in Brain Heart Infusion Broth (Oxoid) supplemented with (/L) haemin (Sigma) $10 \mathrm{mg}$, NAD $10 \mathrm{mg}$ and ethidium bromide (Sigma) $3 \mathrm{mg}$. These cultures were subsequently diluted and spread on DST (Oxoid) agar containing lysed blood $0 \cdot 25 \% \mathrm{v} / \mathrm{v}$ and NAD $10 \mathrm{mg} / \mathrm{L}$ to give single colonies; these were then replica-plated on to agar of the same composition but containing chloramphenicol $2 \mathrm{mg} / \mathrm{L}$.

\section{Results}

\section{CAT activity}

CAT activity was detected in extracts from all the resistant strains. Specific activities were in the range $\left(9 \cdot 2 \times 10^{-3}\right)-\left(1 \times 10^{-1}\right)$ units/mg dry weight (fig. 1), representing a 10 -fold difference between the highest and lowest measurements. In contrast, activities measured in five separate extracts prepared simultaneously from a single culture varied by no more than $\pm 10 \%$ and activities from three sequential overnight cultures of the same strain varied by $\pm 20 \%$. The activities did not correlate with either the diameters of the inhibition zones around $10-\mu \mathrm{g}$ chloramphenicol disks or with the MICs for the strains. Extracts of cultures that had 


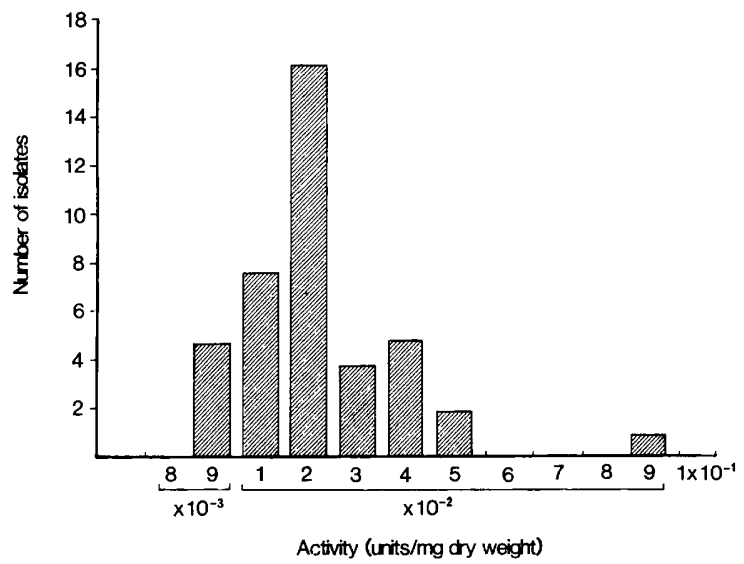

Fig. 1. Distribution of CAT activities in extracts from 42 chloramphenicol-resistant isolates of $H$. influenzae.

been grown in the presence of chloramphenicol $2 \mathrm{mg} / \mathrm{L}$ contained $40-190 \%$ (mean $90 \%$ ) of the levels of specific CAT activity of cultures grown on drugfree media (fig. 2). Extracts made from the three control chloramphenicol-sensitive strains did not contain detectable CAT activity before or after attempted induction.

The CAT activity of all the extracts was reduced by $84-98 \%$ if they were first incubated for $30 \mathrm{~min}$ with $0.5 \mathrm{~mm}$ DTNB. Extracts incubated for $30 \mathrm{~min}$ without DTNB retained almost all of their activity, and adding $0.1 \mathrm{mM}$ chloramphenicol to the extract mixed with DTNB, in the absence of acetylcoenzyme A, largely prevented enzyme inactivation by DTNB during a $30-\mathrm{min}$ incubation period at $37^{\circ} \mathrm{C}$ (fig. 3). Identical behaviour was observed with Type-II CAT from E. coli, whereas the Type-I and Type-III CATs from $E$. coli were largely insensitive to DTNB (table).

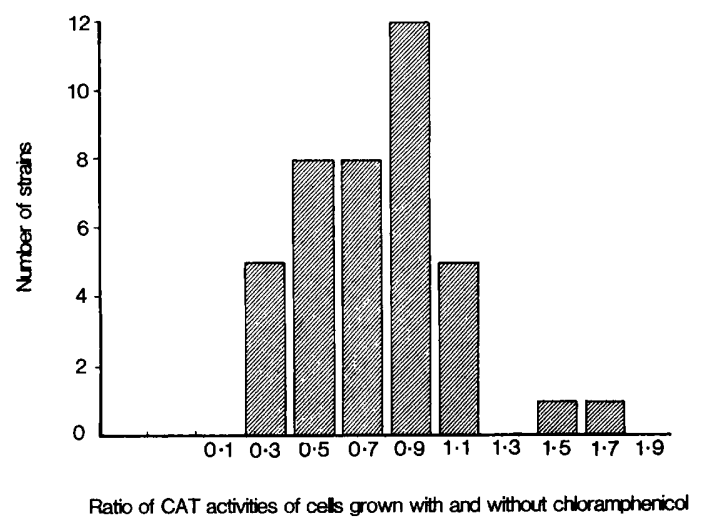

Fig. 2. Comparison of CAT activities, for each strain, grown on heated blood agar with or without chloramphenicol $2 \mathrm{mg} / \mathrm{L}$.

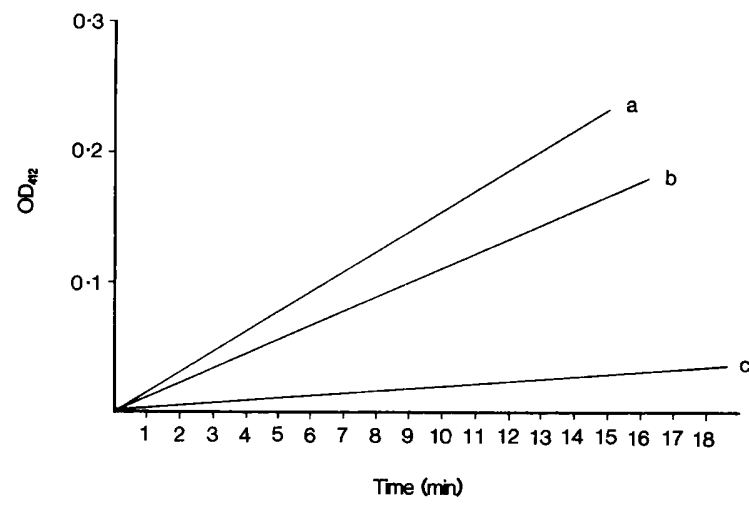

Fig. 3. CAT activity in extracts of $H$. influenzae strain 2976 under the following conditions : (a) chloramphenicol, acetyl CoA and DTNB were mixed and the reaction was started by addition of the enzyme extract; (b) extract, chloramphenicol and DTNB were mixed and incubated together for $30 \mathrm{~min}$ at $37^{\circ} \mathrm{C}$ before addition of the acetyl $\mathrm{CoA}$; (c) extract, acetyl CoA, and DTNB were incubated together for $30 \mathrm{~min}$ at $37^{\circ} \mathrm{C}$ before addition of the chloramphenicol. In each case the reaction was monitored continuously by spectrophotometry at $412 \mathrm{~nm}$, after addition of the last component.

\section{Plasmid profiles and curing}

Only five resistant strains contained plasmids detectable by the method of Kado and Liu (1981). All had mol. wts $c .40 \times 10^{6}$. The strains containing plasmids were not more resistant than plasmid-free strains; the CAT activities measured in the former organisms were scattered within the range observed for all the chloramphenicol-resistant $H$. influenzae. Neither of the two additional methods of plasmid extraction detected extra-chromosomal DNA in the eight strains examined.

When attempts were made to cure three plasmidcontaining strains with ethidium bromide, chloramphenicol-sensitive colonies (MIC $\leqslant 2 \mathrm{mg} / \mathrm{L}$ ) were not obtained. However, screening of chlor-

Table. CAT activity of extracts from reference strains with and without a 30 -min incubation period in the presence of DTNB

Activity* ( $\mathrm{u} / \mathrm{mg}$ dry weight) of extract

\begin{tabular}{lccc}
\cline { 3 - 4 } Strain no. & CAT type & with DTNB & without DTNB \\
\hline 50055 & I & $1.9 \times 10^{-2}$ & $2.0 \times 10^{-2}$ \\
50128 & II & $3.3 \times 10^{-4}$ & $4.0 \times 10^{-3}$ \\
50022 & III & $9.4 \times 10^{-2}$ & $8.3 \times 10^{-2}$
\end{tabular}

* 1 unit acetylated $1 \mu \mathrm{mol}$ of chloramphenicol/min under the defined assay conditions (see Methods). 
amphenicol-resistant colonies by the method of Kado and Liu (1981) revealed that all six colonies of one strain examined and three of six colonies of another were plasmid-free while all six colonies of a third strain still retained their plasmid. The MICs of chloramphenicol, and of tetracycline, trimethoprim and sulphamethoxazole, were unaltered after loss of these plasmids.

\section{Discussion}

All the chloramphenicol-resistant isolates produced CAT, their enzymes resembling Type-II CATs of the enterobacteria in their level of activity and sensitivity to inhibition by DTNB. Other workers have reported CAT, similar to the enteric Type II, in $H$. influenzae, $H$. parainfluenzae and $H$. ducreyi (Roberts et al., 1982, 1985). However, detailed analysis by Roberts et al. (1982) showed that CATs from $H$. influenzae differ from enteric Type-II CATs in some respects and are heterogenous. Zaidenzaig et al. (1979) described a Type-III CAT in $H$. parainfluenzae but there have been no reports of Types-I or -III CATs in $H$. influenzae. Isolates with intrinsic resistance to chloramphenicol were not detected in the present study. Such isolates have been described by Burns et al. (1985) only and there is some suggestion that they may have reduced pathogenicity.

Extrachromosomal DNA was not detected in 37 of the 42 strains examined. This may reflect inadequate detection methods (Roberts and Smith, 1980). However, because three different methods failed to demonstrate plasmids in eight strains and because, in two of the plasmid-carrying strains examined, plasmid loss was not accompanied by changes in resistance to chloramphenicol or any other drug tested, it is likely that the chloramphenicol resistance genes are carried on the chromosome. Evidence from other workers also supports the view that integration of resistance determinants into the chromosome of $H$. influenzae is common. Mendelman et al. (1984), using standard methods, failed to detect extrachromosomal DNA in a $\beta$-lactamaseproducing strain resistant to chloramphenicol and tetracycline and in 17 of 27 (over $60 \%$ ) of its multiresistant transconjugants. Hybridisation experiments showed that the resistance determinants were carried on the chromosomes of both the donor and the 27 transconjugants examined as well as on a previously undetected plasmid present in the donor strain and in one of the transconjugants. Stuy
(1980) studied 25 apparently plasmid-free isolates of $H$. influenzae with a variety of antibiotic resistances and suggested that the genes determining resistance were carried on the chromosome of at least 16 because resistance was transferable to $\mathrm{rec}^{+}$recipients only.

The CAT activities of cultures grown in the presence of chloramphenicol were in the range 40$190 \%$ of the activities of cultures grown in the absence of the drug (fig. 2). These differences exceeded the variation observed $( \pm 20 \%)$ when CAT activity was repeatedly measured in cultures grown in the absence of chloramphenicol, apparently suggesting that the drug did affect the level of detectable enzyme activity. Nonetheless, the effect of the drug was inconsistent, with activity increased in some strains, but reduced in others. Several factors may contribute to this variability. In particular, chloramphenicol is a protein synthesis inhibitor and may affect CAT synthesis. The results provide little evidence to suggest CAT inducibility in $H$. influenzae as with two isolates only did the activity of cells grown in the presence of chloramphenicol exceed that of cells grown in its absence by a factor of 1.5 or more.

The 10-fold range of CAT activity in extracts from different strains was noteworthy, being far outside the assay-to-assay variation. Similar variation was noted by Roberts et al. (1980) who described a 12-fold range of CAT activity between nine chloramphenicol-resistant $H$. influenzae strains. Shaw (1975) described inter-strain differences in the expression of CAT enzymes and suggested that this might be due to gene dosage effects, particularly if the enzyme was plasmidcoded and the copy number varied. Moreover, variations in nutrient supply are known to affect CAT activity in $E$. coli. Although this species produces CAT constitutively, both cAMP and a catabolite activator protein are needed to maintain enzyme synthesis (de Crombrugghe et al., 1973). Such variables may apply for $H$. influenzae and may account not only for strain-to-strain variations but may also be relevant to the effects of exposure to chloramphenicol on CAT activity in some strains.

In conclusion, this study of 42 clinical isolates of $H$. influenzae obtained from a large-scale national survey over a period of 3 months suggests that production of CAT Type II is the most important mechanism of chloramphenicol resistance in the UK and supports the view that resistance determinants are often integrated into the chromosome in this species. 


\section{REFERENCES}

Azemun P, Stull T, Roberts M, Smith A L 1981 Rapid detection of chloramphenicol resistance in Haemophilus influenzae. Antimicrobial Agents and Chemotherapy 20 : 168-170.

Bennett P M, Heritage J, Hawkey P M 1986 An ultra-rapid method for the study of antibiotic resistance plasmids. Journal of Antimicrobial Chemotherapy 18: 421-424.

Burns J L, Mendelman P M, Levy J, Stull T L, Smith A L 1985 A permeability barrier as a mechanism of chloramphenicol resistance in Haemophilus influenzae. Antimicrobial Agents and Chemotherapy 27: 46-54.

de Crombrugghe B, Pastan I, Shaw W V, Rosner J I 1973 Stimulation by cyclic AMP and ppGpp of chloramphenicol acetyl transferase synthesis. Nature New Biology 241 : 237 239.

Kado C I, Liu S T 1981 Rapid procedure for detection and isolation of large and small plasmids. Journal of Bacteriology; 145 : 1365-1373.

Manten A, van Klingeren B, Dessens-Kroon M 1976 Chloramphenicol resistance in Haemophilus influenzae. Lancet 1 : 702.

Mendelman P M, Doroshow C A, Gandy S L, Syriopoulou V, Weigen C P, Smith A L 1984 Plasmid-mediated resistance in multiply resistant Haemophilus influenzae type b causing meningitis: molecular characterization of one strain and review of the literature. Journal of Infectious Diseases 150: 30-39.

Meyers J A, Sanchez D, Elwell L P, Falkow S 1976 Simple agarose gel electrophoretic method for the identification and characterization of plasmid deoxyribonucleic acid. Journal of Bacteriology 127: 1529-1537.

Philpott-Howard J, Williams J D 1982 Increase in antibiotic resistance in Haemophilus influenzae in the United Kingdom since 1977: report of study group. British Medical Journal 284: 1597-1599.

Powell M, Koutsia-Carouzou C, Voutsinas D, Seymour A, Williams J D 1987 Resistance of clinical isolates of Haemophilus influenzae in United Kingdom 1986. Eritish Medical Journal 295: 176-179.

Roberts M C, Swenson C D, Owens L M, Smith A L 1980 Characterization of chloramphenicol-resistant Haemophilus influenzae. Antimicrobial Agents and Chemotherapy 18: 610 615.

Roberts M C, Smith A L 1980 Molecular characterization of "plasmid-free" antibiotic-resistant Haemophilus influenzae. Journal of Bacteriology 144: 476-479.

Roberts M, Corney A, Shaw W V 1982 Molecular characterization of three chloramphenicol acetyltransferases isolated from Haemophilus influenze. Journal of Bacteriology 151: 737-741.

Roberts M C, Actis L A, Crosa J H 1985 Molecular characterization of chloramphenicol-resistant Haemophilus parainfluenzae and Haemophilus ducreyi. Antimicrobial Agents and Chemotherapy 28: 176-180.

Shaw W V, Brodsky R F 1968 Characterization of chloramphenicol acetyltransferase from chloramphenicol resistant Staphylococcus aureus. Journal of Bacteriology 95 : 28-36.

Shaw M V 1975 Chloramphenicol acetyltransferase from chloramphenicol-resistant bacteria. Methods in Enzymology 43: 737-755.

Stuy J H 1980 Chromosomally integrated conjugative plasmids are common in antibiotic-resistant Haemophilus influenzae. Journal of Bacteriology 142: 925-930.

Zaidenzaig Y, Fitton J E, Packman L C, Shaw W V 1979 Characterization and comparison of chloramphenicol acetyltransferase variants. European Journal of Biochemistry 100: 609-618. 